\title{
Adipose tissue macrophage in immune regulation of metabolism
}

\author{
Yifu Qiu ${ }^{1 *}$, Bo Shan ${ }^{2}$, Liu Yang ${ }^{2} \&$ Yong Liu ${ }^{3 * *}$ \\ ${ }^{1}$ Institute of Molecular Medicine, Peking-Tsinghua Center for Life Sciences, Peking University, Beijing 100871, China; \\ ${ }^{2}$ Key Laboratory of Nutrition and Metabolism, Institute for Nutritional Sciences, Shanghai Institutes for Biological Sciences, Chinese Academy \\ of Sciences; University of the Chinese Academy of Sciences, Shanghai 200031, China, \\ ${ }^{3}$ Hubei Key Laboratory of Cell Homeostasis, College of Life Sciences, the Institute for Advanced Studies, Wuhan University, Wuhan 430072, \\ China
}

Received June 3, 2016; accepted September 13, 2016; published online November 9, 2016

\begin{abstract}
The prevalence of obesity and type 2 diabetes is escalating to an epidemic proportion worldwide. Obesity is known to be associated with a state of chronic, low-grade inflammation. Emerging lines of evidence have shown that both innate and adaptive immune responses play crucial roles in the control of metabolic homeostasis. Macrophages in adipose tissues are the essential effector cells in orchestrating metabolic inflammation, which is thought to promote the pathogenic progression of obesity and obesity-related disorders. Here we discuss our current understanding of the distinct modes of activation of adipose tissue macrophages, which can sense the metabolic cues and exert profound effects upon adipose homeostasis. Targeting macrophages in adipose tissues may provide new avenues for developing immunomodulation-based therapeutics against obesity and obesity-associated metabolic diseases.
\end{abstract}

macrophage, adipose tissue, obesity, inflammation, metabolic disease

Citation: $\quad$ Qiu, Y., Shan, B., Yang, L., and Liu, Y. (2016). Adipose tissue macrophage in immune regulation of metabolism. Sci China Life Sci 59, 1232-1240. doi: 10.1007/s11427-016-0155-1

\section{INTRODUCTION}

The prevalence of obesity and obesity-associated metabolic diseases is escalating to an epidemic proportion, not only in industrialized nations but also in developing countries like China (Hossain et al., 2007; Xu et al., 2013; Yang et al., 2010). This brings about a huge financial burden on the public healthcare systems worldwide (Cawley and Meyerhoefer, 2012). Characterized by an excess fat accumulation with serious medical consequences, obesity represents a major risk factor for a variety of metabolic diseases, including type 2 diabetes mellitus, cardiovascular diseases, and certain types of cancer. For example, around $80 \%$ of the incidence of type

*Corresponding author (email: yifu.qiu@pku.edu.cn)

**Corresponding author (email: liuyong31279@whu.edu.cn)
2 diabetes can be attributed to the increasing rates of obesity and overweight (McNelis and Olefsky, 2014). It has been estimated that type 2 diabetes can account for about 3.4 million deaths per year worldwide, and more than $80 \%$ of diabetesrelated deaths occur in less developed countries including China (World Health Organization, http://www.who.int/mediacentre/factsheets/fs312/en/). Therefore, it is of paramount importance to improve our understanding of the mechanisms underlying the pathogenesis of obesity and related metabolic dysfunctions, which will pave the way towards new strategies to combat these devastating metabolic diseases.

Investigating the immune aspects of metabolic homeostasis is a rapidly burgeoning field, largely prompted by the recognition of obesity as a chronic inflammatory disorder. Obesity was initially found to be associated with a state of low-grade inflammation, which is believed to promote 
the pathogenic development of insulin resistance and type 2 diabetes (Hotamisligil, 2006). Aiming to understand the functional intersection of immunity and metabolism, an increasing number of recent studies have uncovered the critical roles for various cell types of the immune system in the homeostatic control of metabolism (Brestoff and Artis, 2015). Macrophages, in particular, are the critical effector cells in orchestrating inflammation and have been most extensively investigated with respect to their roles in obesity-associated metabolic inflammation and insulin resistance (McNelis and Olefsky, 2014). In response to changes of the nutritional status and metabolic cues, tissue-resident macrophages have been documented to exert profound metabolic effects in various metabolic organs, including white/brown adipose tissues, liver and pancreas (Eguchi et al., 2012; Ehses et al., 2007; Kang et al., 2008; Nguyen et al., 2011; Odegaard et al., 2008; Qiu et al., 2014). In addition to macrophages, other innate immune cells such as mast cells, neutrophils, eosinophils, group 2 innate lymphoid cells (Liu et al., 2009; Molofsky et al., 2013; Talukdar et al., 2012; Wu et al., 2011), as well as adaptive immune cells including $\mathrm{T}$ cells and $\mathrm{B}$ cells (Cipolletta et al., 2012; Feuerer et al., 2009; Lynch et al., 2012; Winer et al., 2009; Winer et al., 2011), have all been found in adipose tissues and were shown to be involved in obesity-related metabolic dysfunctions. Adipose tissues comprise multiple types including white, brown and beige fat, and they play pivotal roles in metabolic homeostasis (Rosen and Spiegelman, 2014). In this review, we focus on the metabolic activation and functional properties of adipose tissue macrophage (ATM). Gaining a better understanding of the pathogenic and/or protective roles of ATM may offer translational opportunities for developing novel therapeutics against obesity, type 2 diabetes and other related metabolic diseases.

\section{TISSUE-RESIDENT MACROPHAGES}

Macrophages are the integral components of mammalian tissues, arising from hematopoietic or embryonic sources. Tissue-resident macrophages are phenotypically heterogeneous population of immune cells that exert a broad range of tissue-specific and niche-specific functions (Davies et al., 2013). Tissue-resident macrophages play key roles not only in host defense, but also in tissue development and homeostasis (Davies et al., 2013; Okabe and Medzhitov, 2016). They can respond to tissue damages and orchestrate tissue-repair responses (Mantovani et al., 2004). Given their exceptional phagocytic ability, it is not surprising that tissue-resident macrophages are critical in the clearance of apoptotic cells and in the remodeling of the extracellular matrix (Okabe and Medzhitov, 2016). In addition, tissue-resident macrophages can serve as a crucial source of growth factors for other cell types (Pollard, 2009). It has been shown that macrophages are functionally implicated in tissue patterning and branching (Dai et al., 2002; Pollard, 2009; Stefater et al., 2011). Macrophages can engulf extruded erythrocyte nuclei during erythropoiesis, and the lack of this phagocytosis results in blockage of erythropoiesis and lethality (Kawane et al., 2001). Macrophages have also been shown to determine haematopoietic egress from bone marrow (Jaiswal et al., 2009) and maintain the haematopoietic steady state through phagocytosis of neutrophils and erythrocytes in the spleen and liver (Gordy et al., 2011). Osteoclasts, the bone macrophages, are known to be required for bone resorption and remodeling (Pollard, 2009). Interestingly, macrophages have also been suggested to play a role in stem cell regulation of tissue homeostasis. For example, macrophages have been implicated in specifying hepatic progenitor cell fate during liver regeneration (Boulter et al., 2012), and in remodeling the enlarging white adipose tissue to facilitate nutrient storage in adipocytes (Sun et al., 2011). Given the broad range of their essential functions, tissue-resident macrophages have been connected to a variety of pathological conditions, including obesity, type 2 diabetes, atherosclerosis, and cancers (Okabe and Medzhitov, 2016).

\section{ATM IN OBESITY-ASSOCIATED METABOLIC INFLAMMATION}

Obesity-associated chronic inflammation, also known as "metaflammation", is mainly mediated by both innate and adaptive immune cells (Chawla et al., 2011; Hotamisligil, 2006). The initial seminal findings by Spiegelman's group indicated a crucial link between obesity, obesity-induced insulin resistance and inflammation. In those studies, inflammatory cytokines, such as tumor necrosis factor (TNF), were found to be produced from the adipose tissue, which could in turn elicit local and systemic insulin resistance through serine phosphorylation of insulin receptor substrate 1 (IRS1) (Hotamisligil et al., 1996; Hotamisligil et al., 1993). A number of follow-up studies revealed the involvement of other pro-inflammatory cytokines in obesity-associated adipose inflammation, including interleukin-6 (IL-6) and IL-1 $\beta$ (Pradhan et al., 2001; Wen et al., 2011). Importantly, it was further demonstrated that infiltrating macrophages, but not adipocytes, are the primary contributor of metaflammation (Weisberg et al., 2003; Xu et al., 2003a). Moreover, in the setting of obesity, macrophages were shown to exhibit an altered localization within the adipose tissue, as well as an activation switch from the anti-inflammatory to pro-inflammatory phenotypes (Lumeng et al., 2007a; Lumeng et al., 2007b; Nguyen et al., 2007). These important findings lead to the notion that ATMs may have direct endocrine or paracrine effects to communicate with adipocytes, thereby playing critical parts in the regulation of adipose homeostasis and systemic metabolism. 


\section{FUNCTIONAL CHARACTERISTICS OF M1 AND M2 MACROPHAGES}

Macrophages are known to sense cues of tissue microenvironment and undergo reprogramming to display a spectrum of distinct activation phenotypes (Martinez et al., 2006). Macrophages have been frequently grouped into two functional categories: the classically activated macrophages and the alternatively activated macrophages, also termed M1 and M2 macrophages (Gordon, 2003). M1 macrophages $\left(\mathrm{NOS}^{+} \mathrm{TNF}^{+}\right)$can be activated by type 1 cytokines such as interferon- $\gamma$ (IFN- $\gamma$ ) to produce the pro-inflammatory cytokines like TNF- $\alpha$, IL- 6 and IL- $1 \beta$, whereas M2 macrophages $\left(\mathrm{ARG} 1^{+} \mathrm{CD} 206^{+} \mathrm{CD} 301^{+}\right)$are activated by type 2 cytokines such as IL-4 and IL-13 to secret the anti-inflammatory cytokines like IL-10 (Chawla et al., 2011; Gordon, 2003; Lumeng et al., 2007a; Lumeng et al., 2008; Mathis, 2013; Odegaard and Chawla, 2011; Odegaard et al., 2007). However, it should be noted that there exist various activation states ranging from the supreme M1 to M2 phenotypes, and therefore, the current M1/M2 categorization is oversimplified for precisely delineating their activation characteristics under various physiological and pathological states (Chawla et al., 2011; Murray et al., 2014).

Macrophages can respond to a variety of signals derived from microbes, activated lymphocytes, or damaged tissues, thereby performing a diversity of functions in host defense as well as in tissue homeostasis, including adipose tissues (Brestoff and Artis, 2015). In the lean state, the anti-inflammatory M2 macrophages predominate and disperse uniformly throughout the white adipose tissue (WAT), which can secrete IL-10 and are thought to promote insulin sensitivity through mechanisms that remain to be deciphered (Chawla et al., 2011). In the state of obesity, however, the pro-inflammatory M1 macrophages are primarily present in the WAT, which are thought to be differentiated from recruited CCR $2^{+} \mathrm{CD} 11 \mathrm{c}^{+}$monocytes and macrophages (Chawla et al., 2011). Genetic manipulation studies showed that enhancing or inhibiting the recruitment of CCR2 $2^{+} \mathrm{Ly} 6 \mathrm{C}^{\text {hi }}$ monocytes into the WAT could lead to insulin resistance or improvement of insulin sensitivity, respectively (Arkan et al., 2005; Kamei et al., 2006; Weisberg et al., 2006). Interestingly, the M1 macrophages have often been found to circumscribe adipocytes undergoing apoptosis/necrosis and form a "crown-like" structure. They are believed to elicit adipose tissue inflammation and subsequent insulin resistance through producing inflammatory mediators such as TNF- $\alpha$, Nos2 and IL-6 (Cinti et al., 2005; Lumeng et al., 2007a).

\section{CRITICAL REGULATORY FACTORS AND PATHWAYS IN M1/M2 POLARIZATION}

Many studies have revealed the critical regulatory cascades that are involved in governing the M1/M2 polarization. These contain cellular signaling components that receive and respond to extracellular signals, including ligands, receptors, kinases and transcriptional factors. The M1 polarization axis involves receptors such as IL-1R, tumor necrosis factor receptor (TNFR) and Toll-like receptor 2/4 (TLR2/4), which can sense IL-1 $\beta$, TNF- $\alpha$, saturated free fatty acids and lipopolysaccharides (LPS), respectively, and trigger the

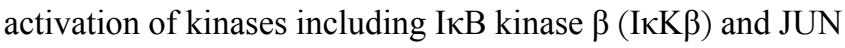
$\mathrm{N}$-terminal kinase (JNK). This subsequently leads to the activation of transcriptional factors such as nuclear factor $\kappa \mathrm{B}$ $(\mathrm{NF}-\kappa \mathrm{B}), \mathrm{c}-\mathrm{JUN}$, interferon regulatory factor 3 (IRF3) and IRF5, thereby promoting the expression of pro-inflammatory genes (Arkan et al., 2005; Konner and Bruning, 2011; Solinas et al., 2007; Vandanmagsar et al., 2011). The M2 polarization axis is thought to be mainly mediated by the actions of type 2 cytokines IL-4 and IL-13, IL-4R, and transcriptional factors including signal transducer and activator of transcription 6 (STAT6), peroxisome proliferator-activated receptor $\gamma$ ( PPAR $\gamma$ ), PPAR $\delta$ and Krüppel-like factor 4 (KLF4) (Gordon, 2003; Kang et al., 2008; Liao et al., 2011; O'Neill and Bowie, 2007; Odegaard et al., 2007; Odegaard et al., 2008). Recently, IRF4 and HIF1 $\alpha$ were also reported to control the M2 polarization of ATM and tumor-associated macrophages, respectively (Colegio et al., 2014; Eguchi et al., 2013). More mechanistic investigations will be needed to delineate how the interplays and cross-talks between these regulatory components in the M1/M2 polarization program can be influenced by changes in the microenvironment of tissues, e.g. in adipose tissues during handling of excess nutrients.

\section{METABOLIC ACTIONS OF M1/M2 MACROPHAGES IN FAT TISSUES}

Tissue-resident macrophages, as well as other types of immune cells, can exert profound regulatory effects upon adipocyte functions. The recruitment, differentiation, and even survival of ATMs are regulated in response to the microenvironmental cues, and the M1/M2 polarized activation of ATMs is functionally connected to the metabolic output of fat tissues (Figure 1). In the face of overnutrition, excess nutrients are mainly stored in adipocytes in the form of fat, and such chronic energy imbalance leads to increased adiposity and ultimately, obesity. It has been established that, in addition to serving as a storage depot for excess energy, adipocytes also function as dynamic endocrine cells to produce both pro-inflammatory and anti-inflammatory bioactive molecules, thereby affecting insulin sensitivity in adipose tissues locally and in other metabolic tissues systematically (Rosen and Spiegelman, 2014). In obese human subjects as well as in rodent models of obesity, it has been documented that adipocytes can release inflammatory mediators such as 
A M1 macrophage
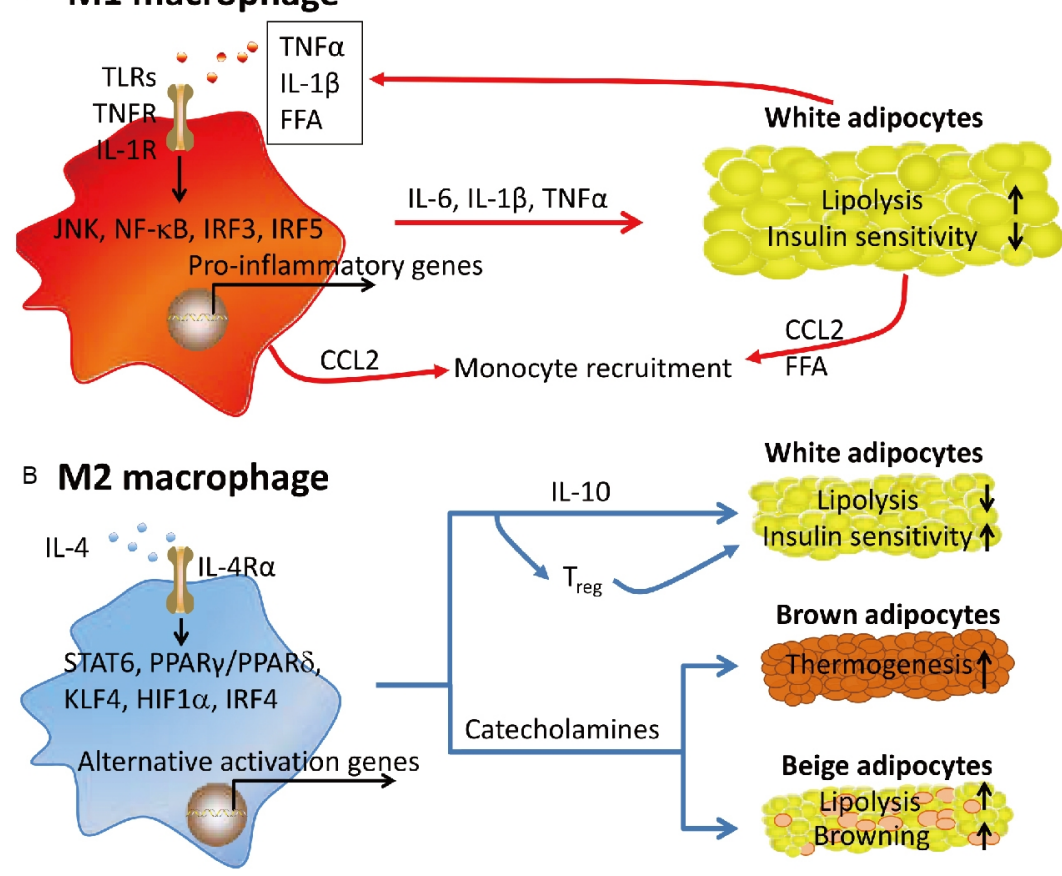

Figure 1 Metabolic actions of M1 versus M2 macrophages in adipose tissues. A, M1 macrophages act to elicit adipose inflammation and insulin resistance. In the state of obesity, monocytes and macrophages are recruited into WAT and lead to increased production and secretion of inflammatory molecules, which subsequently initiate the pro-inflammatory signaling cascades. These signaling events not only induce more inflammatory cytokines to inhibit the insulin sensitivity of adipocytes, but also further promote the inflammatory response by recruiting more inflammatory monocytes that can differentiate into M1 macrophages. In such a feed-forward vicious cycle, adipocyte-derived saturated free fatty acids, pro-inflammatory cytokines and chemokines act to sustain and enhance the inflammatory state of WAT. B, M2 macrophages act to suppress WAT inflammation and promote insulin sensitivity. IL-4 induces M2 activation through the STAT6 pathway as well as the transcriptional program that involves upregulation of PPAR $\gamma$, PPAR $\delta$, KLF4, IRF4, and HIF1 $\alpha$ (hypoxia-inducible factor 1 $\alpha$ ). These transcriptional factors cooperate to establish and maintain the alternative activation state of ATMs. M2 macrophages and Treg cells can produce and secret IL-10 to enhance insulin sensitivity and inhibit lipolysis in WAT. In addition, M2 macrophages may directly secret catecholamines to activate brown fat and induce beige fat formation (i.e. browning) within WAT, thereby promoting adaptive thermogenesis and energy expenditure.

CC-chemokine ligand 2 (CCL2), TNF- $\alpha$, leukotriene B4 (LTB4) and free fatty acids, which act to promote the recruitment of monocytes and their differentiation and/or activation into ATMs (Olefsky and Glass, 2010; Weisberg et al., 2006; Xu et al., 2003a). These infiltrated macrophages, together with resident ATMs, exhibit a polarized activation state resembling the M1 phenotype, which produce more inflammatory cytokines (e.g. TNF- $\alpha$, IL-6 and IL-1 $\beta$ ). Such a feed-forward vicious cycle is believed to be responsible for the unresolved chronic adipose inflammation, which in turn causes systemic insulin resistance (Lumeng et al., 2007a; Sica and Mantovani, 2012; Weisberg et al., 2006). In lean adipose tissues, however, resident macrophages exhibit the phenotype of M2 polarized activation, which is under the control of type 2 cytokines like IL-4 and IL-13 (Odegaard and Chawla, 2013; Van Dyken and Locksley, 2013; Wu et al., 2011). M2 macrophages in non-obese individuals were proposed to be involved in maintaining adipose tissue homeostasis and promoting insulin sensitivity through their anti-inflammatory actions (Odegaard et al., 2007; Sica and Mantovani, 2012; Wu et al., 2011). Animal model studies also indicated that M2 macrophages in the lean state can produce and secret large amounts of IL-10 and other me- diators, which are likely to be critical for the maintenance of both adipocyte insulin sensitivity and the general anti-inflammatory microenvironment in adipose tissues (Lumeng et al., 2007a; Odegaard and Chawla, 2013). Supporting the crucial roles of M1/M2 macrophages in the pathogenesis of metabolic disorders, GWAS studies have revealed positive correlations between the genetic loci of the M1/M2 signaling components and type $1 / 2$ diabetes as well as cardiovascular diseases (Table 1).

Intriguingly, a series of recently reported studies suggest that M2 macrophages in adipose tissues may have key roles in nonshivering adaptive thermogenesis (Odegaard and Chawla, 2015). Nguyen et al. demonstrated that in the adaptive response to lower environmental temperatures, macrophages resident in both brown and white adipose tissues could be activated towards the M2 state; such M2 polarized activation of ATMs could in turn produce and secret catecholamines, thereby inducing the thermogenic program in brown fat while eliciting lipolysis in white fat to support the adaptive thermogenesis (Nguyen et al., 2011). Furthermore, through producing catecholamines, the M2-polarized ATMs could promote browning or beige cell formation within subcutaneous WAT (scWAT), which is less innervated but highly prone to brown- 
Table 1 Correlation between macrophage activation-associated genes and metabolic diseases

\begin{tabular}{|c|c|c|}
\hline Genes & Metabolic diseases & Reference \\
\hline $\begin{array}{l}\text { IL-4 promoter polymorphism } \\
\text { (IL-4 C-589T and C-34T) }\end{array}$ & Type 2 diabetes & (Ho et al., 2010) \\
\hline $\begin{array}{l}\text { IL-4 promoter polymorphism } \\
\text { (IL-4-589 C/C) }\end{array}$ & $\begin{array}{l}\text { Lower circulatory high-density lipoprotein } \\
\text { cholesterol level (HDL-C) }\end{array}$ & (Ho et al., 2010) \\
\hline $\begin{array}{l}\text { IL-4R } \alpha \text { polymorphism } \\
\quad(\text { IL-4R } \alpha \text { E400A) }\end{array}$ & Dysfunction of lipid metabolism & (Chang et al., 2012) \\
\hline IL-4R $\alpha$, IL-4 and IL-13 loci & Type 1 diabetes & (Bugawan et al., 2003) \\
\hline IL-4 locus & Type 2 diabetes & (Ban et al., 2010) \\
\hline $\begin{array}{l}\text { IL-6 single nucleotide polymorphism } \\
\text { (IL-6C-174G) }\end{array}$ & Type 2 diabetes & (Illig et al., 2005) \\
\hline $\begin{array}{l}\text { CCL2 and CCR2 polymorphism } \\
\text { (CCL2 G-2518A), CCR2 (Val64Ile) }\end{array}$ & Insulin resistance & (Guzman-Ornelas et al., 2016) \\
\hline TLR4 variants & High TC/HDL-C & (Kolz et al., 2008) \\
\hline
\end{tabular}

ing in response to the cold challenge or hormonal stimulation (Hui et al., 2015; Qiu et al., 2014). In accordance, elevated production of meteorin-like protein (Metrnl) in adipose tissue upon cold exposure and in muscle after exercise training, was recently shown to exert beneficial effects upon energy expenditure, adipose inflammation, and glucose metabolism through inducing the production of eosinophil-derived IL-4, which could in turn promote the M2 activation of ATMs and browning of scWAT (Rao et al., 2014). Further dissecting the diversity and dynamics of ATMs will provide more insights into our understanding of the molecular and cellular basis of immune regulation of adaptive thermogenesis and metabolic homeostasis.

In the state of obesity, white adipocytes can produce pro-inflammatory factors such as free fatty acids (FFAs), TNF $\alpha$ and CCL2, to create an M1-prone microenvironment to favor M1 activation. Likewise, hypertrophic brown adipocytes can produce such factors to promote M1 activation as well (Olefsky and Glass, 2010; Weisberg et al., 2006; Xu et al., 2003a). Interestingly, obesity was found to be associated with reduced expression of tyrosine hydroxylase and consequently, lower production of catecholamines both in scWAT and epididymal WAT (eWAT), whereas high levels of tyrosine hydroxylase expression and catecholamine production were found in brown adipose tissue (BAT), which could support local lipolysis and HFD-induced thermogenesis as an adaptive defense response (Qiu et al., 2014). This distinct thermogenic response might stem from the rich sympathetic innervation within BAT (Slavin and Ballard, 1978; Weiner et al., 1962).

\section{MULTI-FACTORIAL MODULATION OF ATM ACTIVATION}

As the central site for nutrient-handling and energy storage, adipose tissues are subjected to constant metabolic remodeling along with changes of metabolite fluxes. Emerging lines of evidence suggest that activation of ATMs can be influenced by various metabolic and microbial signals that constitute the microenvironment cues in adipose tissues. For instance, branched fatty acid esters of hydroxy fatty acids were recently identified as important regulatory molecules in glucose metabolism, at least partially through affecting ATM activation (Yore et al., 2014). In addition, other metabolic tissues such as the muscle, liver, and particularly gut microorganisms, also communicate with adipose tissues and influence the activation profiles of ATMs. An increasing number of studies in both animal models and human subjects have clearly demonstrated that gut microbiota play crucial roles in host systemic inflammation and metabolic health (Tremaroli and Bäckhed, 2012). Profiling of microbial communities has revealed that the human gut microbiota consist of 100 trillion archaeal and bacterial cells with over 1,000 species (Qin et al., 2010). The gut microbial community was shown to be dominated by five bacterial phyla and one Archaea, with more than $90 \%$ of the species belonging to Firmicutes and Bacteroidetes. While each person has a distinct and highly variable microbiota, a conserved core gut microbiota has been found to be shared among individuals (Qin et al., 2010; Turnbaugh et al., 2009). As a critical environmental factor that affects host energy metabolism, the gut microbiota is known to be critical during food digestion and energy absorption (Samuel and Gordon, 2006), providing enzymes to degrade most complex carbohydrates and plant polysaccharides (Martens et al., 2011; Xu et al., 2003b). It is also known that non-digestible carbohydrates can be fermented in the colon to yield energy and end-products such as short-chain fatty acids (SCFAs) (Bergman, 1990). While exerting a profound impact upon gut health, SCFAs, including acetate, propionate and butyrate, can enter circu- 
lation and act as signaling molecules to affect the function of peripheral tissues such as adipose tissues (Canfora et al., 2015). For example, SCFAs were shown to influence the intracellular lipolytic activity (Aberdein et al., 2014; Ge et al., 2008) and adipocyte differentiation (Haberland et al., 2010; Li et al., 2014). Moreover, incubation of human adipose tissue with propionate was reported to result in decreased expression and secretion of pro-inflammatory cytokines and chemokines (Al-Lahham et al., 2012). More importantly, gut-derived pro-inflammatory molecules can interact with distinct intracellular pattern recognition receptors of the immune cells, e.g. LPS with TLR4 and peptidoglycan (PGN) with nucleotide oligomerization domain (NOD) proteins, respectively, triggering systemic inflammation and whole-body insulin resistance (Amar et al., 2011; Cani et al., 2007; Schertzer et al., 2011). Circulating LPS levels were found to increase dramatically in patients with type 2 diabetes (Creely et al., 2007), and continuous subcutaneous infusion of LPS in mice was also documented to cause adipose tissue inflammation and insulin resistance (Cani et al., 2007). Given that colonization of germ-free mice with Escherichia coli could lead to the accumulation of macrophages in WAT and their polarization towards the M1 phenotype (Caesar et al., 2012), it is not surprising that gut microbiota may exert profound actions upon metabolic homeostasis through modulating the activation profiles of ATMs.

\section{PERSPECTIVES}

It is well established that chronic, low-grade inflammation plays an essential role in the homeostatic regulation of the function of adipose tissue (locally) and other metabolic tissues (systemically). Based on the notion that pro-inflammatory immune cells such as macrophages can secret pro-inflammatory molecules to inhibit insulin sensitivity in metabolic tissues, anti-inflammatory drugs or strategies are believed to be effective for the treatment of insulin resistance and type 2 diabetes. Unfortunately, results from such clinical trials have been disappointing (Esser et al., 2015). This is not surprising, however, since inflammatory responses are also known to play beneficial roles in certain physiological contexts. Phagocytic macrophages function to engulf dead adipocytes to avoid necrosis and the attendant M1 activation, leading to a type 2 bias of the microenvironment (e.g. enhancing the M2 activation of macrophages) (Odegaard and Chawla, 2013). Of interesting note, it was recently reported that adipocyte inflammation is required for the proper remodeling and healthy expansion of the adipose tissue upon high-fat diet feeding, thereby safely storing extra nutrients and effectively filtering gut-derived endotoxins (Wernstedt Asterholm et al., 2014). Thus, it needs to be reconsidered how the ATM-mediated immune-metabolism axis should be targeted, taking into account not only how to suppress the pro-inflammatory M1 activation but also how to combine and balance with the anti-inflammatory M2 activation and the associated type 2 immunity. This is rational because type 2 immunity, including M2 macrophages, has been implicated in the control of adaptive thermogenesis. Modulating the shift from the M1 to M2 activation, and more broadly the switch from type 1 to type 2 immunity, has been proposed as a novel strategy for the development of therapeutics against obesity and obesity-related metabolic disorders. This notion has shown great promise in the early clinical or preclinical studies that aimed to restore the regulatory $\mathrm{T}$ (Treg) population and healthy gut microbiota through biasing the type 2 microenvironment (Turnbaugh et al., 2006; Winer et al., 2009). Furthermore, the oversimplified opinion regarding insulin resistance as a foe may also need to be reconsidered, which can in fact be viewed as an adaptive response to famine while being required to fuel immune responses (Odegaard and Chawla, 2013). Therefore, it should be more effective to target the fundamental regulatory nodes in energy imbalance that root many aspects of metabolic syndrome, including diabetes, cardiovascular diseases and even some types of cancers (Cao, 2010; Gesta et al., 2007). With these in mind, we believe a better understanding of ATM biology and immune regulation of metabolism holds tremendous promise for therapeutic treatment of obesity and its associated diseases.

Compliance and ethics The author(s) declare that they have no conflict of interest.

Acknowledgements This work was supported by the National Natural Science Foundation of China (81420108006, 31230036) to Yong Liu, and the Thousand Young Talents Program of the Chinese government to Yifu Qiu.

Aberdein, N., Schweizer, M., and Ball, D. (2014). Sodium acetate decreases phosphorylation of hormone sensitive lipase in isoproterenol-stimulated 3T3-L1 mature adipocytes. Adipocyte 3, 121-125.

Al-Lahham, S., Roelofsen, H., Rezaee, F., Weening, D., Hoek, A., Vonk, R., and Venema, K. (2012). Propionic acid affects immune status and metabolism in adipose tissue from overweight subjects. Eur J Clin Invest 42, 357-364

Amar, J., Chabo, C., Waget, A., Klopp, P., Vachoux, C., Bermúdez-Humarán, L.G., Smirnova, N., Bergé, M., Sulpice, T., Lahtinen, S., Ouwehand, A., Langella, P., Rautonen, N., Sansonetti, P.J., and Burcelin, R. (2011). Intestinal mucosal adherence and translocation of commensal bacteria at the early onset of type 2 diabetes: molecular mechanisms and probiotic treatment. EMBO Mol Med 3, 559-572.

Arkan, M.C., Hevener, A.L., Greten, F.R., Maeda, S., Li, Z.W., Long, J.M., Wynshaw-Boris, A., Poli, G., Olefsky, J., and Karin, M. (2005). IкK- $\beta$ links inflammation to obesity-induced insulin resistance. Nat Med 11, 191-198.

Ban, H.J., Heo, J.Y., Oh, K.S., and Park, K.J. (2010). Identification of type 2 diabetes-associated combination of SNPs using support vector machine. BMC Genet 11, 26.

Bergman, E.N. (1990). Energy contributions of volatile fatty acids from the gastrointestinal tract in various species. Physiol Rev 70, 567-590.

Boulter, L., Govaere, O., Bird, T.G., Radulescu, S., Ramachandran, P., 
Pellicoro, A., Ridgway, R.A., Seo, S.S., Spee, B., Van Rooijen, N., Sansom, O.J., Iredale, J.P., Lowell, S., Roskams, T., and Forbes, S.J. (2012). Macrophage-derived Wnt opposes Notch signaling to specify hepatic progenitor cell fate in chronic liver disease. Nat Med 18, 572-579.

Brestoff, J.R., and Artis, D. (2015). Immune regulation of metabolic homeostasis in health and disease. Cell 161, 146-160.

Bugawan, T.L., Mirel, D.B., Valdes, A.M., Panelo, A., Pozzilli, P., and Erlich, H.A. (2003). Association and interaction of the IL4R, IL4, and IL13 loci with type 1 diabetes among Filipinos. Am J Hum Genet 72, 1505-1514.

Caesar, R., Reigstad, C.S., Bäckhed, H.K., Reinhardt, C., Ketonen, M., Östergren Lundén, G., Cani, P.D., and Bäckhed, F. (2012). Gut-derived lipopolysaccharide augments adipose macrophage accumulation but is not essential for impaired glucose or insulin tolerance in mice. Gut 61, 1701-1707.

Canfora, E.E., Jocken, J.W., and Blaak, E.E. (2015). Short-chain fatty acids in control of body weight and insulin sensitivity. Nat Rev Endocrinol 11, 577-591.

Cani, P.D., Amar, J., Iglesias, M.A., Poggi, M., Knauf, C., Bastelica, D., Neyrinck, A.M., Fava, F., Tuohy, K.M., Chabo, C., Waget, A., Delmee, E., Cousin, B., Sulpice, T., Chamontin, B., Ferrieres, J., Tanti, J.F., Gibson, G.R., Casteilla, L., Delzenne, N.M., Alessi, M.C., and Burcelin, R. (2007). Metabolic endotoxemia initiates obesity and insulin resistance. Diabetes 56, 1761-1772.

Cao, Y. (2010). Adipose tissue angiogenesis as a therapeutic target for obesity and metabolic diseases. Nat Rev Drug Discov 9, 107-115.

Cawley, J., and Meyerhoefer, C. (2012). The medical care costs of obesity: an instrumental variables approach. J Health Econ 31, 219-230.

Chang, Y.H., Huang, C.N., and Shiau, M.Y. (2012). Association of IL-4 receptor gene polymorphisms with high density lipoprotein cholesterol. Cytokine 59, 309-312.

Chawla, A., Nguyen, K.D., and Goh, Y.P.S. (2011). Macrophage-mediated inflammation in metabolic disease. Nat Rev Immunol 11, 738-749.

Cinti, S. (2005). Adipocyte death defines macrophage localization and function in adipose tissue of obese mice and humans. J Lipid Res 46, 2347-2355.

Cipolletta, D., Feuerer, M., Li, A., Kamei, N., Lee, J., Shoelson, S.E., Benoist, C., and Mathis, D. (2012). PPAR- $\gamma$ is a major driver of the accumulation and phenotype of adipose tissue Treg cells. Nature 486, 549-553.

Colegio, O.R., Chu, N.Q., Szabo, A.L., Chu, T., Rhebergen, A.M., Jairam, V., Cyrus, N., Brokowski, C.E., Eisenbarth, S.C., Phillips, G.M., Cline, G.W., Phillips, A.J., and Medzhitov, R. (2014). Functional polarization of tumour-associated macrophages by tumour-derived lactic acid. Nature 513, 559-563.

Creely, S.J., McTernan, P.G., Kusminski, C.M., Fisher, M., Da Silva, N.F., Khanolkar, M., Evans, M., Harte, A.L., and Kumar, S. (2007). Lipopolysaccharide activates an innate immune system response in human adipose tissue in obesity and type 2 diabetes. Am J Physiol Endocrinol Metab 292, E740-E747.

Dai, X.M., Ryan, G.R., Hapel, A.J., Dominguez, M.G., Russell, R.G., Kapp, S., Sylvestre, V., and Stanley, E.R. (2002). Targeted disruption of the mouse colony-stimulating factor 1 receptor gene results in osteopetrosis, mononuclear phagocyte deficiency, increased primitive progenitor cell frequencies, and reproductive defects. Blood 99, 111-120.

Davies, L.C., Jenkins, S.J., Allen, J.E., and Taylor, P.R. (2013). Tissueresident macrophages. Nat Immunol 14, 986-995.

Eguchi, J., Kong, X., Tenta, M., Wang, X., Kang, S., and Rosen, E.D. (2013). Interferon regulatory factor 4 regulates obesity-induced inflammation through regulation of adipose tissue macrophage polarization. Diabetes 62, 3394-3403.

Eguchi, K., Manabe, I., Oishi-Tanaka, Y., Ohsugi, M., Kono, N., Ogata, F., Yagi, N., Ohto, U., Kimoto, M., Miyake, K., Tobe, K., Arai, H., Kadowaki, T., and Nagai, R. (2012). Saturated fatty acid and TLR signaling link $\beta$ cell dysfunction and islet inflammation. Cell Metab 15,
518-533.

Ehses, J.A., Perren, A., Eppler, E., Ribaux, P., Pospisilik, J.A., Maor-Cahn, R., Gueripel, X., Ellingsgaard, H., Schneider, M.K.J., Biollaz, G., Fontana, A., Reinecke, M., Homo-Delarche, F., and Donath, M.Y. (2007). Increased number of islet-associated macrophages in type 2 diabetes. Diabetes 56, 2356-2370.

Esser, N., Paquot, N., and Scheen, A.J. (2015). Anti-inflammatory agents to treat or prevent type 2 diabetes, metabolic syndrome and cardiovascular disease. Expert Opin Invest Drugs 24, 283-307.

Feuerer, M., Herrero, L., Cipolletta, D., Naaz, A., Wong, J., Nayer, A., Lee, J., Goldfine, A.B., Benoist, C., Shoelson, S., and Mathis, D. (2009). Lean, but not obese, fat is enriched for a unique population of regulatory T cells that affect metabolic parameters. Nat Med 15, 930-939.

Ge, H., Li, X., Weiszmann, J., Wang, P., Baribault, H., Chen, J.L., Tian, H., and Li, Y. (2008). Activation of $\mathrm{G}$ protein-coupled receptor 43 in adipocytes leads to inhibition of lipolysis and suppression of plasma free fatty acids. Endocrinology 149, 4519-4526.

Gesta, S., Tseng, Y.H., and Kahn, C.R. (2007). Developmental origin of fat: tracking obesity to its source. Cell 131, 242-256.

Gordon, S. (2003). Alternative activation of macrophages. Nat Rev Immunol 3, 23-35.

Gordy, C., Pua, H., Sempowski, G.D., and He, Y.W. (2011). Regulation of steady-state neutrophil homeostasis by macrophages. Blood 117, 618-629.

Guzman-Ornelas, M.O., Petri, M.H., Vazquez-Del Mercado, M., Chavarria-Avila, E., Corona-Meraz, F.I., Ruiz-Quezada, S.L., Madrigal-Ruiz, P.M., Castro-Albarran, J., Sandoval-Garcia, F., and Navarro-Hernandez, R.E. (2016). CCL2 serum levels and adiposity are associated with the polymorphic phenotypes -2518 A on CCL2 and 64ILE on CCR2 in a mexican population with insulin resistance. J Diabetes Res 2016, doi: 10.1155/2016/5675739.

Haberland, M., Carrer, M., Mokalled, M.H., Montgomery, R.L., and Olson, E.N. (2010). Redundant control of adipogenesis by histone deacetylases 1 and 2. J Biol Chem 285, 14663-14670.

Ho, K.T., Shiau, M.Y., Chang, Y.H., Chen, C.M., Yang, S.C., and Huang, C.N. (2010). Association of interleukin-4 promoter polymorphisms in Taiwanese patients with type 2 diabetes mellitus. Metabolism 59, 1717-1722.

Hossain, P., Kawar, B., and El Nahas, M. (2007). Obesity and diabetes in the developing world-a growing challenge. N Engl J Med 356, 213-215.

Hotamisligil, G.S. (2006). Inflammation and metabolic disorders. Nature 444, 860-867.

Hotamisligil, G.S., Peraldi, P., Budavari, A., Ellis, R., White, M.F., and Spiegelman, B.M. (1996). IRS-1-mediated inhibition of insulin receptor tyrosine kinase activity in TNF-alpha- and obesity-induced insulin resistance. Science 271, 665-670.

Hotamisligil, G.S., Shargill, N.S., and Spiegelman, B.M. (1993). Adipose expression of tumor necrosis factor-alpha: direct role in obesity-linked insulin resistance. Science 259, 87-91.

Hui, X., Gu, P., Zhang, J., Nie, T., Pan, Y., Wu, D., Feng, T., Zhong, C., Wang, Y., Lam, K.S.L., and Xu, A. (2015). Adiponectin enhances cold-induced browning of subcutaneous adipose tissue via promoting M2 macrophage proliferation. Cell Metab 22, 279-290.

Illig, T., Bongardt, F., Schöpfer-Wendels, A., Huth, C., Heid, I., Rathmann, W., Martin, S., Vollmert, C., Holle, R., Thorand, B., Wichmann, H., Koenig, W., Kolb, H., and Herder, C. (2005). Genetics of type 2 diabetes: impact of interleukin-6 gene variants. Gesundheitswesen 67, 122-126.

Jaiswal, S., Jamieson, C.H.M., Pang, W.W., Park, C.Y., Chao, M.P., Majeti, R., Traver, D., van Rooijen, N., and Weissman, I.L. (2009). CD47 is upregulated on circulating hematopoietic stem cells and leukemia cells to avoid phagocytosis. Cell 138, 271-285.

Kamei, N. (2006). Overexpression of monocyte chemoattractant protein-1 in adipose tissues causes macrophage recruitment and insulin resistance. J Biol Chem 281, 26602-26614.

Kang, K., Reilly, S.M., Karabacak, V., Gangl, M.R., Fitzgerald, K., Hatano, B., and Lee, C.H. (2008). Adipocyte-derived Th2 cytokines and myeloid 
$\operatorname{PPAR} \delta$ regulate macrophage polarization and insulin sensitivity. Cell Metab 7, 485-495.

Kawane, K., Fukuyama, H., Kondoh, G., Takeda, J., Ohsawa, Y., Uchiyama, Y., and Nagata, S. (2001). Requirement of DNase II for definitive erythropoiesis in the mouse fetal liver. Science 292, 1546-1549.

Kolz, M., Baumert, J., Müller, M., Khuseyinova, N., Klopp, N., Thorand, B., Meisinger, C., Herder, C., Koenig, W., and Illig, T. (2008). Association between variations in the TLR4gene and incident type 2 diabetes is modified by the ratio of total cholesterol to HDL-cholesterol. BMC Med Genet 9, 9.

Könner, A.C., and Brüning, J.C. (2011). Toll-like receptors: linking inflammation to metabolism. Trends Endocrinol Metab 22, 16-23.

Li, G., Yao, W., and Jiang, H. (2014). Short-chain fatty acids enhance adipocyte differentiation in the stromal vascular fraction of porcine adipose tissue. J Nutr 144, 1887-1895.

Liao, X., Sharma, N., Kapadia, F., Zhou, G., Lu, Y., Hong, H., Paruchuri, K., Mahabeleshwar, G.H., Dalmas, E., Venteclef, N., Flask, C.A., Kim, J., Doreian, B.W., Lu, K.Q., Kaestner, K.H., Hamik, A., Clément, K., and Jain, M.K. (2011). Krüppel-like factor 4 regulates macrophage polarization. J Clin Invest 121, 2736-2749.

Liu, J., Divoux, A., Sun, J., Zhang, J., Clément, K., Glickman, J.N., Sukhova, G.K., Wolters, P.J., Du, J., Gorgun, C.Z., Doria, A., Libby, P., Blumberg, R.S., Kahn, B.B., Hotamisligil, G.S., and Shi, G.P. (2009). Genetic deficiency and pharmacological stabilization of mast cells reduce diet-induced obesity and diabetes in mice. Nat Med 15, 940-945.

Lumeng, C.N., Bodzin, J.L., and Saltiel, A.R. (2007a). Obesity induces a phenotypic switch in adipose tissue macrophage polarization. J Clin Invest $117,175-184$.

Lumeng, C.N., DelProposto, J.B., Westcott, D.J., and Saltiel, A.R. (2008). Phenotypic switching of adipose tissue macrophages with obesity is generated by spatiotemporal differences in macrophage subtypes. Diabetes 57, 3239-3246.

Lumeng, C.N., DeYoung, S.M., Bodzin, J.L., and Saltiel, A.R. (2007b). Increased inflammatory properties of adipose tissue macrophages recruited during diet-induced obesity. Diabetes 56, 16-23.

Lynch, L., Nowak, M., Varghese, B., Clark, J., Hogan, A.E., Toxavidis, V., Balk, S.P., O'Shea, D., O'Farrelly, C., and Exley, M.A. (2012). Adipose tissue invariant NKT cells protect against diet-induced obesity and metabolic disorder through regulatory cytokine production. Immunity 37, 574-587

Mantovani, A., Sica, A., Sozzani, S., Allavena, P., Vecchi, A., and Locati, M. (2004). The chemokine system in diverse forms of macrophage activation and polarization. Trends Immunol 25, 677-686.

Martens, E.C., Lowe, E.C., Chiang, H., Pudlo, N.A., Wu, M., McNulty, N.P., Abbott, D.W., Henrissat, B., Gilbert, H.J., Bolam, D.N., Gordon, J.I., and Eisen, J.A. (2011). Recognition and degradation of plant cell wall polysaccharides by two human gut symbionts. PLoS Biol 9, e1001221.

Martinez, F.O., Gordon, S., Locati, M., and Mantovani, A. (2006). Transcriptional profiling of the human monocyte-to-macrophage differentiation and polarization: new molecules and patterns of gene expression. $\mathrm{J}$ Immunol 177, 7303-7311.

Mathis, D. (2013). Immunological goings-on in visceral adipose tissue. Cell Metab 17, 851-859.

McNelis, J.C., and Olefsky, J.M. (2014). Macrophages, immunity, and metabolic disease. Immun 41, 36-48.

Mirel, D.B., Valdes, A.M., Lazzeroni, L.C., Reynolds, R.L., Erlich, H.A., and Noble, J.A. (2002). Association of IL4R haplotypes with type 1 diabetes. Diabetes 51, 3336-3341.

Molofsky, A.B., Nussbaum, J.C., Liang, H.E., Van Dyken, S.J., Cheng, L.E., Mohapatra, A., Chawla, A., and Locksley, R.M. (2013). Innate lymphoid type 2 cells sustain visceral adipose tissue eosinophils and alternatively activated macrophages. J Exp Med 210, 535-549.

Murray, P.J., Allen, J.E., Biswas, S.K., Fisher, E.A., Gilroy, D.W., Goerdt, S., Gordon, S., Hamilton, J.A., Ivashkiv, L.B., Lawrence, T., Locati, M., Mantovani, A., Martinez, F.O., Mege, J.L., Mosser, D.M., Natoli,
G., Saeij, J.P., Schultze, J.L., Shirey, K.A., Sica, A., Suttles, J., Udalova, I., van Ginderachter, J.A., Vogel, S.N., and Wynn, T.A. (2014). Macrophage activation and polarization: nomenclature and experimental guidelines. Immunity 41, 14-20.

Nguyen, K.D., Qiu, Y., Cui, X., Goh, Y.P.S., Mwangi, J., David, T., Mukundan, L., Brombacher, F., Locksley, R.M., and Chawla, A. (2011). Alternatively activated macrophages produce catecholamines to sustain adaptive thermogenesis. Nature 480, 104-108.

Nguyen, M.T.A., Favelyukis, S., Nguyen, A.K., Reichart, D., Scott, P.A., Jenn, A., Liu-Bryan, R., Glass, C.K., Neels, J.G., and Olefsky, J.M. (2007). A subpopulation of macrophages infiltrates hypertrophic adipose tissue and is activated by free fatty acids via Toll-like receptors 2 and 4 and JNK-dependent pathways. J Biol Chem 282, 35279-35292.

O'Neill, L.A.J., and Bowie, A.G. (2007). The family of five: TIR-domaincontaining adaptors in Toll-like receptor signalling. Nat Rev Immunol 7, 353-364.

Odegaard, J.I., and Chawla, A. (2011). Alternative macrophage activation and metabolism. Annu Rev Pathol Mech Dis 6, 275-297.

Odegaard, J.I., and Chawla, A. (2013). Pleiotropic actions of insulin resistance and inflammation in metabolic homeostasis. Science 339, $172-177$.

Odegaard, J.I., and Chawla, A. (2015). Type 2 responses at the interface between immunity and fat metabolism. Curr Opin Immunol 36, 67-72.

Odegaard, J.I., Ricardo-Gonzalez, R.R., Goforth, M.H., Morel, C.R., Subramanian, V., Mukundan, L., Eagle, A.R., Vats, D., Brombacher, F., Ferrante, A.W., and Chawla, A. (2007). Macrophage-specific PPAR $\gamma$ controls alternative activation and improves insulin resistance. Nature 447, 1116-1120.

Odegaard, J.I., Ricardo-Gonzalez, R.R., Red Eagle, A., Vats, D., Morel, C.R., Goforth, M.H., Subramanian, V., Mukundan, L., Ferrante, A.W., and Chawla, A. (2008). Alternative M2 activation of Kupffer cells by PPAR $\delta$ ameliorates obesity-induced insulin resistance. Cell Metab 7, $496-507$.

Okabe, Y., and Medzhitov, R. (2016). Tissue biology perspective on macrophages. Nat Immunol 17, 9-17.

Olefsky, J.M., and Glass, C.K. (2010). Macrophages, inflammation, and insulin resistance. Annu Rev Physiol 72, 219-246.

Pollard, J.W. (2009). Trophic macrophages in development and disease. Nat Rev Immunol 9, 259-270.

Pradhan, A.D., Manson, J.E., Rifai, N., Buring, J.E., and Ridker, P.M. (2001). C-reactive protein, interleukin 6, and risk of developing type 2 diabetes mellitus. JAMA 286, 327-334.

Qin, J., Li, R., Raes, J., Arumugam, M., Burgdorf, K.S., Manichanh, C., Nielsen, T., Pons, N., Levenez, F., Yamada, T., Mende, D.R., Li, J., Xu, J., Li, S., Li, D., Cao, J., Wang, B., Liang, H., Zheng, H., Xie, Y., Tap, J., Lepage, P., Bertalan, M., Batto, J.M., Hansen, T., Le Paslier, D., Linneberg, A., Nielsen, H.B., Pelletier, E., Renault, P., Sicheritz-Ponten, T., Turner, K., Zhu, H., Yu, C., Li, S., Jian, M., Zhou, Y., Li, Y., Zhang, X., Li, S., Qin, N., Yang, H., Wang, J., Brunak, S., Doré, J., Guarner, F., Kristiansen, K., Pedersen, O., Parkhill, J., Weissenbach, J., MetaHIT Consortium, Bork, P., Ehrlich, S.D., and Wang, J. (2010). A human gut microbial gene catalogue established by metagenomic sequencing. Nature 464, 59-65.

Qiu, Y., Nguyen, K.D., Odegaard, J.I., Cui, X., Tian, X., Locksley, R.M., Palmiter, R.D., and Chawla, A. (2014). Eosinophils and type 2 cytokine signaling in macrophages orchestrate development of functional beige fat. Cell 157, 1292-1308.

Rao, R.R., Long, J.Z., White, J.P., Svensson, K.J., Lou, J., Lokurkar, I., Jedrychowski, M.P., Ruas, J.L., Wrann, C.D., Lo, J.C., Camera, D.M., Lachey, J., Gygi, S., Seehra, J., Hawley, J.A., and Spiegelman, B.M. (2014). Meteorin-like is a hormone that regulates immune-adipose interactions to increase beige fat thermogenesis. Cell 157, 1279-1291.

Rosen, E.D., and Spiegelman, B.M. (2014). What we talk about when we talk about fat. Cell 156, 20-44.

Samuel, B.S., and Gordon, J.I. (2006). A humanized gnotobiotic mouse 
model of host-archaeal-bacterial mutualism. Proc Natl Acad Sci USA 103, 10011-10016.

Schertzer, J.D., Tamrakar, A.K., Magalhaes, J.G., Pereira, S., Bilan, P.J., Fullerton, M.D., Liu, Z., Steinberg, G.R., Giacca, A., Philpott, D.J., and Klip, A. (2011). NOD1 activators link innate immunity to insulin resistance. Diabetes 60, 2206-2215.

Sica, A., and Mantovani, A. (2012). Macrophage plasticity and polarization: in vivo veritas. J Clin Invest 122, 787-795.

Slavin, B.G., and Ballard, K.W. (1978). Morphological studies on the adrenergic innervation of white adipose tissue. Anat Rec 191, 377-389.

Solinas, G., Vilcu, C., Neels, J.G., Bandyopadhyay, G.K., Luo, J.L., Naugler, W., Grivennikov, S., Wynshaw-Boris, A., Scadeng, M., Olefsky, J.M., and Karin, M. (2007). JNK1 in hematopoietically derived cells contributes to diet-induced inflammation and insulin resistance without affecting obesity. Cell Metab 6, 386-397.

Stefater, J.A., 3rd, Ren, S., Lang, R.A., and Duffield, J.S. (2011). Metchnikoff's policemen: macrophages in development, homeostasis and regeneration. Trends Mol Med 17, 743-752.

Sun, C., Zhi, D., Shen, S., Luo, F., and Sanjeevi, C.B. (2014). SNPs in the exons of Toll-like receptors are associated with susceptibility to type 1 diabetes in Chinese population. Hum Immunol 75, 1084-1088.

Sun, K., Kusminski, C.M., and Scherer, P.E. (2011). Adipose tissue remodeling and obesity. J Clin Invest 121, 2094-2101.

Talukdar, S., Oh, D.Y., Bandyopadhyay, G., Li, D., Xu, J., McNelis, J., Lu, M., Li, P., Yan, Q., Zhu, Y., Ofrecio, J., Lin, M., Brenner, M.B., and Olefsky, J.M. (2012). Neutrophils mediate insulin resistance in mice fed a high-fat diet through secreted elastase. Nat Med 18, 1407-1412.

Tremaroli, V., and Bäckhed, F. (2012). Functional interactions between the gut microbiota and host metabolism. Nature 489, 242-249.

Turnbaugh, P.J., Hamady, M., Yatsunenko, T., Cantarel, B.L., Duncan, A., Ley, R.E., Sogin, M.L., Jones, W.J., Roe, B.A., Affourtit, J.P., Egholm, M., Henrissat, B., Heath, A.C., Knight, R., and Gordon, J.I. (2009). A core gut microbiome in obese and lean twins. Nature 457, 480-484.

Turnbaugh, P.J., Ley, R.E., Mahowald, M.A., Magrini, V., Mardis, E.R., and Gordon, J.I. (2006). An obesity-associated gut microbiome with increased capacity for energy harvest. Nature 444, 1027-131.

Van Dyken, S.J., and Locksley, R.M. (2013). Interleukin-4- and interleukin13-mediated alternatively activated macrophages: roles in homeostasis and disease. Annu Rev Immunol 31, 317-343.

Vandanmagsar, B., Youm, Y.H., Ravussin, A., Galgani, J.E., Stadler, K., Mynatt, R.L., Ravussin, E., Stephens, J.M., and Dixit, V.D. (2011). The NLRP3 inflammasome instigates obesity-induced inflammation and insulin resistance. Nat Med 17, 179-188.

Weiner, N., Perkins, M., and Sidman, R.L. (1962). Effect of reserpine on noradrenaline content of innervated and denervated brown adipose tissue of the rat. Nature 193, 137-138.

Weisberg, S.P., Hunter, D., Huber, R., Lemieux, J., Slaymaker, S., Vaddi, K., Charo, I., Leibel, R.L., and Jr., A.W.F. (2006). CCR2 modulates inflammatory and metabolic effects of high-fat feeding. J Clin Invest

\section{$116,115-124$.}

Weisberg, S.P., McCann, D., Desai, M., Rosenbaum, M., Leibel, R.L., and Ferrante Jr., A.W. (2003). Obesity is associated with macrophage accumulation in adipose tissue. J Clin Invest 112, 1796-1808.

Wen, H., Gris, D., Lei, Y., Jha, S., Zhang, L., Huang, M.T.H., Brickey, W.J., and Ting, J.P.Y. (2011). Fatty acid-induced NLRP3-ASC inflammasome activation interferes with insulin signaling. Nat Immunol 12, 408-415.

Wernstedt Asterholm, I., Tao, C., Morley, T.S., Wang, Q.A., Delgado-Lopez, F., Wang, Z.V., and Scherer, P.E. (2014). Adipocyte inflammation is essential for healthy adipose tissue expansion and remodeling. Cell Metab 20, 103-118.

Winer, D.A., Winer, S., Shen, L., Wadia, P.P., Yantha, J., Paltser, G., Tsui, H., Wu, P., Davidson, M.G., Alonso, M.N., Leong, H.X., Glassford, A., Caimol, M., Kenkel, J.A., Tedder, T.F., McLaughlin, T., Miklos, D.B., Dosch, H.M., and Engleman, E.G. (2011). B cells promote insulin resistance through modulation of $\mathrm{T}$ cells and production of pathogenic $\mathrm{IgG}$ antibodies. Nat Med 17, 610-617.

Winer, S., Chan, Y., Paltser, G., Truong, D., Tsui, H., Bahrami, J., Dorfman, R., Wang, Y., Zielenski, J., Mastronardi, F., Maezawa, Y., Drucker, D.J., Engleman, E., Winer, D., and Dosch, H.M. (2009). Normalization of obesity-associated insulin resistance through immunotherapy. Nat Med 15, 921-929.

Wu, D., Molofsky, A.B., Liang, H.E., Ricardo-Gonzalez, R.R., Jouihan, H.A., Bando, J.K., Chawla, A., and Locksley, R.M. (2011). Eosinophils sustain adipose alternatively activated macrophages associated with glucose homeostasis. Science 332, 243-247.

Xu, H., Barnes, G.T., Yang, Q., Tan, G., Yang, D., Chou, C.J., Sole, J., Nichols, A., Ross, J.S., Tartaglia, L.A., and Chen, H. (2003a). Chronic inflammation in fat plays a crucial role in the development of obesityrelated insulin resistance. J Clin Invest 112, 1821-1830.

Xu, J., Bjursell, M.K., Himrod, J., Deng, S., Carmichael, L.K., Chiang, H.C., Hooper, L.V., and Gordon, J.I. (2003b). A genomic view of the humanbacteroides thetaiotaomicron symbiosis. Science 299, 2074-2076.

Xu, Y., Wang, L., He, J., Bi, Y., Li, M., Wang, T., Wang, L., Jiang, Y., Dai, M., Lu, J., Xu, M., Li, Y., Hu, N., Li, J., Mi, S., Chen, C.S., Li, G., Mu, Y., Zhao, J., Kong, L., Chen, J., Lai, S., Wang, W., Zhao, W., Ning, G., and 2010 China Noncommunicable Disease Surveillance Group. (2013). Prevalence and control of diabetes in Chinese adults. JAMA 310, 948.

Yang, W., Lu, J., Weng, J., Jia, W., Ji, L., Xiao, J., Shan, Z., Liu, J., Tian, H., Ji, Q., Zhu, D., Ge, J., Lin, L., Chen, L., Guo, X., Zhao, Z., Li, Q., Zhou, Z., Shan, G., He, J., and China National Diabetes and Metabolic Disorders Study Group. (2010). Prevalence of diabetes among men and women in China. N Engl J Med 362, 1090-1101.

Yore, M.M., Syed, I., Moraes-Vieira, P.M., Zhang, T., Herman, M.A., Homan, E.A., Patel, R.T., Lee, J., Chen, S., Peroni, O.D., Dhaneshwar, A.S., Hammarstedt, A., Smith, U., McGraw, T.E., Saghatelian, A., and Kahn, B.B. (2014). Discovery of a class of endogenous mammalian lipids with anti-diabetic and anti-inflammatory effects. Cell 159, $318-332$.

Open Access This article is distributed under the terms of the Creative Commons Attribution License which permits any use, distribution, and reproduction in any medium, provided the original author(s) and source are credited. 